Goldschmidt 2021 Abstract

https://doi.org/10.7185/gold2021.7463

\section{Can Compositional Changes In Riverine Chemistry Monitor Geochemical Regime Shifts?}

DR. CATERINA GOZZI, PHD ${ }^{1}$, VASILIS DAKOS ${ }^{2}$, ANTONELLA BUCCIANTI ${ }^{1,3}$, ORLANDO VASELLI ${ }^{1,3}$ AND ROBERTA SAURO GRAZIANO ${ }^{1}$

${ }^{1}$ University of Florence

${ }^{2}$ ISEM, CNRS, Université de Montpellier, EPHE, IRD

${ }^{3}$ CNR-IGG Institute of Geosciences and Earth Resources

Presenting Author: caterina.gozzi@unifi.it

An ever-growing research effort has been carried out to identify thresholds and regime shifts, particularly for a wide range of ecological systems [1], [2]. However, the study of regime shifts, to the best of our knowledge, has never been applied to river geochemistry. Abrupt changes in the system state (composition) of a certain environmental media, driven by external or inner perturbations, may trigger Geochemical Regime Shifts (GRSs). This work intends to propose a new holistic way of thinking about river geochemistry focused on environmental interconnections with hydro-litho-morphologic and anthropoclimate pressures rather than single chemical variables. We present river water composition as a response variable resulting from the combined action of environmental drivers and catchment attributes (Fig.1).

The aim of the present study is to verify whether spatial GRSs can be identified in the water chemistry of the Tiber River, the third-longest Italian river. Compositional Data Analysis, robust Principal Component Analysis and score-distance graphs investigate data variability and the interlinks between response and forcing variables within the different watersheds delineated from the Digital Elevation Model.

As a result, a potential regime shift was detected for major species in the lower reaches, where, from a relative prevalence of $\mathrm{N}$-bearing species, the composition radically changes towards a dominance of $\mathrm{Na}^{+}$and $\mathrm{Cl}^{-}$. The regime shifts scenarios of [1], suggest that the observed shift might result from a threshold-like state response caused by the geological forcing. On the contrary, trace elements respond gradually to environmental pressures, showing no abrupt changes. The non-conservative nature of $\mathrm{Fe}$, $\mathrm{Mn}$ and $\mathrm{Ba}$ in the aqueous phase and water-sediment exchange could be responsible for their more stable pattern. The research provides new insights for future multi-disciplinary studies at catchment-scale and for the protection of river system's selfrestoring capability in a fast-changing planet.

[1] Andersen, Carstensen, Hernandez-Garcia \& Duarte (2008). Trends Ecol. Evol., 24, 49-57.

[2] Beaugrand (2004), Prog. Oceanogr. 60 (2-4), 245-262.

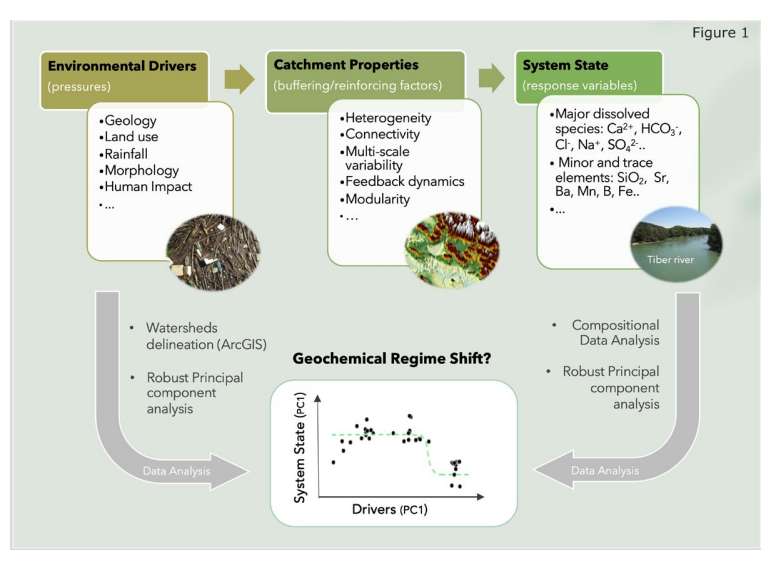

